\title{
Development of Fintech Sector in Turkey
}

\author{
Semih Serkant Aktuğa \\ a Siirt University, Country,
} semihaktug@siirt.edu.tr,

https://orcid.org/ 0000-0002-9745-0010

\section{ARTICLE INFO}

Research Article

2020, Vol. 2(3), 487-499

e-ISSN 2667-5927

Article History:

Received: 01.01.2020

Revised: 29.01.2020

Accepted: 16.02 .2020

Available Online: 15.07 .2020

JEL Code: B26, G29

Keywords: fintech, innovation, Turkey.

Anahtar Kelimeler: fintech, yenilik, Türkiye.
Development of Fintech Sector in Turkey

Abstract

Today, the financial sector is facing great changes. Innovations in financial technology are leading us to a new era of destruction. In a more competitive environment than ever, identifying tomorrow's winners and losers will be the key to capitalizing on the potential growth of the fintech industry. In recent years, the number of daily financial transactions has steadily increased, and digital payments are increasingly being incorporated into routine operations. Shopping on social media platforms, transferring money through messaging applications, and paying in the car using voice control have become a vision, not a future. The pace of innovation is increasing and customers want to make secure financial transactions anywhere, anytime, on any platform. Financial companies are also aware of how fast consumer behavior is changing. This article attempt to evaluate the development of the fintech sector in Turkey.

Türkiye'de Fintech Sektörünün Gelişimi

$\ddot{O z}$

Günümüzde finans sektörü büyük değişikliklerle karşı karşıyadır. Finansal teknolojideki yenilikler bizi yeni bir yıkım çağına sürüklüyor. Her zamankinden daha rekabetçi bir ortamda, yarının kazananlarını ve kaybedenlerini belirlemek, fintech endüstrisinin potansiyel büyümesinden faydalanmanın anahtarı olacaktır. Son yıllarda, günlük finansal işlemlerin sayısı istikrarlı bir şekilde artmıştır ve dijital ödemeler gittikçe artan bir şekilde rutin faaliyetlere dahil edilmektedir. Sosyal medya platformlarında alışveriş yapmak, mesajlaşma uygulamalarıla para aktarmak ve ses kontrolünü kullanarak arabada ödeme yapmak artık bir gelecek değil, bir vizyon haline gelmiştir. Inovasyonun hızı artıyor ve müşteriler her yerde, her zaman, her platformda güvenli finansal işlemler yapmak istiyorlar. Finansal şirketler de tüketici davranışının ne kadar hızlı değiştiğinin farkındadır. Bu makalede fintech sektörünün Türkiye'de gelişimi değerlendirilmeye çalışılmaktadır. 
Aktuğ, S.S. (2020). Development of Fintech Sector in Turkey, BILTURK, The Journal of Economics and Related Studies, 2(3), 487-499.

\section{Giriş}

Küresel ekonomi ölçeğinde, yeniliklerin artan önemi ve teknolojilerin geniş kullanımı dünya çapında bankacılık sektörünü değiştirmektedir. Finansal teknolojiler (Fintech) bankacılığın ayrılmaz bir parçası haline gelmiştir ve günümüzde bankalar, örneğin ödeme hizmetleri sunan finansal olmayan kuruluşların artan rekabetiyle karşı karşıya kalan finansal hizmetlerin ötesinde rekabet etmeye başlamıştır. Başlangıçta hizmet sağlayıcıları, arama motorları ve sosyal ağlar, hizmetlerini geleneksel olarak bankaların kapsadığı alanlara "müdahale ederek" genişletmiştir.

Fintech'in hızlı yükselişi, bankacılıkta iş ortamını değiştirerek daha yenilikçi çözümler istemektedir. Bu son eğilimler bankaların Fintech'e yatırımlarını artırmasını, özellikle de hizmetten tüketicilere hizmet dağıtım kanallarını yeniden düşünmesini, arka ofis işlevlerinin daha fazla standardizasyonunu artırmasını vb. gerektirmektedir. Finansal hizmetler endüstrisinin bazı üyeleri Fintech'teki patlamayı şu şekilde görüyor: Fintech, geleneksel bankacılık endüstrisi için bir tehdittir. Diğer yaklaşımlar ise, Fintech'in daha fazla esneklik ve bazı alanlarda daha iyi işlevsellik sağladığı için fırsata dönüştürülebilecek bir alan haline geldiğini savunmaktadır.

Türkiye'de de Fintech sektörü hızlı bir gelişim göstermektedir. Türk Fintech sektörünün en yenilikçi alanları arka ofis operasyonları, dijital bankacılık, e-ticaret, kimlik yönetimi, ödeme ve sigortacılık uygulamalarıdır.

\section{Fintech Kavramı}

Ödemeler, para transferi, kripto para, portföy yönetimi, kredi, fonlama, faturalama, muhasebe gibi parasal işlemlerde pratiklik, düşük maliyet gibi avantajlarla banka gibi klasik finans kurumlarına alternatif olarak ortaya çıkan şirketler, finansal teknolojiler, kısaca fintechler olarak popüler bir sektör haline gelmiştir.

Fintech için bir çok tanım yapılmış olsa da olguyu tam ve kesin olarak ifade eden bir tanımlama bulunmamaktadır, hatta bunda bir sınırlama durumu da söz konusu değildir (Dorfleitner et al., 2017: 5). "Fintech" finansal teknoloji teriminin kısaltması olup, modern ve yenilikçi teknolojilerle finansal hizmetleri bir araya getiren firmaları ifade etmektedir" (Dorfleitner et al., 2017: 5), "Fintech'ler iş modellerinde teknolojik ve finansal özellikleri birleştiren şirketlerdir." (Eickhoff, Weinrich, Muntermann, 2017: 1), "Fintech kelimesi finansal hizmetler sektörünü daha erişilebilir ve kolay hale getirecek ve alt üst edecek yenilikçi iş modelleri ile teknolojiyi birleştiren şirketleri anlatmaktadır." (Beşli vd., 2018: 8)

Fintech'in tanımı üzerine yapılan bir araştırma, Fintech'in "finansal faaliyetleri iyileştirmek için teknoloji uygulayan yeni bir finans endüstrisi olduğu" sonucuna varmaktadır (Sanicola, 2017). Fintech yeni uygulamalar, süreçler, bir veya daha fazla tamamlayıcı finansal hizmetten oluşan ve internet üzerinden uçtan uca bir süreç olarak sağlanan finansal hizmetler sektöründeki ürünler veya iş modelleri olarak da 
tanımlanmaktadır (Schueffel, 2017: 33). Fintech farklı iş durumlarına göre teknoloji çözümleri önererek finansal hizmet süreçlerini geliştiren herhangi bir yenilikçi fikir olarak düşünülebilmektedir (Leong \& Sung, 2018: 75).

İş dünyasında girişimci ve yatırımcıların yoğun ilgisini çeken sektör, günümüz ekonomik ve sosyal hayatındaki değişimlere koşut müşteri tutum ve beklentilerine hitab eder nitelikte olmak durumundadır (Menteş, 2019: 52). Bu yönden “Finansal teknolojinin kısaltması olan Fintech, finansal hizmetlerin ve ürünlerin tasarım ve sunumunda teknolojinin yenilikçi kullanımına atıfta bulunan geniş bir kategoridir. Fintech, finansal hizmetlerde yeniliği destekleyen teknolojiler için şemsiye bir terimdir diyebiliriz." (Softtech Teknoloji Raporu, 2019: 163), ve bu açıdan da "Finansal piyasalar ve kuruluşlar üstünde bütüncül bir etkiye sahip ve finansal hizmetleri karşılayan ürünler yeni iş modelleri, uygulamalar, süreçler ile sonuçlanan teknolojik olarak olanak sağlayan finansal inovasyonlar" (BCBS, 2018: 8) Fintech olarak ifade edilebilir ve bu perspektifle Fintech için bankalara alternatif veya paydaş/partner olarak, finansal-parasal işlerle iştigal eden, telekomünikasyon ve bilişim teknolojisinin etkin kullanımını esas alarak mobil cihazlar ve internet ortamında çalışan, müşteri/kullanıcı nezdinde de kurum imajından ziyade bir uygulama niteliği taşıyan, yenilikçi ve dinamik firmalar ve iş modelleridir; bir iş ekosistemidir diyebiliriz.

Makine öğrenimi/yapay zekâ, tahmine dayalı davranışsal analitik ve veriye dayalı pazarlama gibi yeni teknolojiler finansal kararlar alınmasında yaygınlaşmaktadır. Özellikle yapay zeka uygulamaları, sadece kullanıcılarının alışkanlıklarını öğrenmekle kalmaz, aynı zamanda kullanıcılarının otomatik, bilinçsiz harcamalarını ve tasarruf kararlarını daha iyi hale getirmek için kullanıcıları öğrenme oyunlarına dahil eder. Fintech ayrıca, müşterilere temel görevlerde yardımcı olmak ve personel maliyetlerini düşürmek için chatbot'ları (sohbet robotu) ve yapay zekâ arayüzlerini kullanan otomatik bir müşteri hizmetleri teknolojisinin aracıdır. (Schueffel, 2017: 34 vd.).

Yapay zekâ, blok zincir ve büyük veri analitiği gibi teknolojiler marifetiyle hizmetleri mesai ve kapalı alan dışına taşıyan (Menteş, 2019: 50) Fintechlerin iş yaratma kapasitesi olarak bu sektörde yaratılan her bir işin beş dolaylı iş yarattığı ve toplamda 2025'e değin 95 milyon iş sağlayacağı ileri sürülmektedir (Yes Bank, 2018: 3). Aşağıdaki Tablo 1'de fintech uygulama örnekleri görülebilir. 
Aktuğ, S.S. (2020). Development of Fintech Sector in Turkey, BILTURK, The Journal of Economics and Related Studies, 2(3), 487-499.

Tablo 1: Fintech Uygulama Örnekleri

\begin{tabular}{|c|c|c|c|c|c|c|}
\hline $\begin{array}{c}\text { Sağlayıcı } \\
\text { Türü }\end{array}$ & $\begin{array}{c}\text { Etkileşim } \\
\text { Türü }\end{array}$ & Danışmanlık & Ödemeler & Yatırımlar & Finansman & Çapraz işlem \\
\hline \multirow[t]{2}{*}{ Banka } & B2C & $\begin{array}{c}\text { Video konfera } \\
\text { ns }\end{array}$ & $\begin{array}{l}\text { Sosyal } \\
\text { medya } \\
\text { ödemesi }\end{array}$ & Robo danışma & $\begin{array}{c}\text { Online kre } \\
\text { di başvuru } \\
\text { su }\end{array}$ & $\begin{array}{l}\text { Online } \\
\text { banka } \\
\text { hesabı } \\
\text { açılışı }\end{array}$ \\
\hline & $\mathrm{C} 2 \mathrm{C}$ & $\begin{array}{l}\text { Çevrimiçi } \\
\text { müşteri } \\
\text { topluluğu }\end{array}$ & Eş ödeme & $\begin{array}{l}\text { Topluma } \\
\text { dayalı } \\
\text { faiz oranı }\end{array}$ & $\begin{array}{c}\text { Crowdlend } \\
\text { ing }\end{array}$ & Sosyal ağ \\
\hline \multirow{3}{*}{$\begin{array}{l}\text { Banka } \\
\text { Dışı }\end{array}$} & $\mathrm{B} 2 \mathrm{C}$ & $\begin{array}{l}\text { Kişisel } \\
\text { finans } \\
\text { yönetimi }\end{array}$ & $\begin{array}{l}\text { Kripto } \\
\text { para } \\
\text { birimi }\end{array}$ & $\begin{array}{c}\text { Çok varlıklı tica } \\
\text { ret }\end{array}$ & $\begin{array}{l}\text { Kurumsal k } \\
\text { rediler }\end{array}$ & $\begin{array}{c}\text { Elektronik } \\
\text { veri } \\
\text { kasası }\end{array}$ \\
\hline & $\mathrm{C} 2 \mathrm{C}$ & $\begin{array}{c}\text { Topluluk } \\
\text { temelli } \\
\text { danışmanlık }\end{array}$ & Mobil Ödeme & Convesting & $\begin{array}{c}\text { Crowdlend } \\
\text { ing }\end{array}$ & $\begin{array}{l}\text { Sadakat } \\
\text { puanları }\end{array}$ \\
\hline & B2B & $\begin{array}{l}\text { Dijital } \\
\text { müşteri } \\
\text { tavsiyesi }\end{array}$ & $\begin{array}{l}\text { Kişisel } \\
\text { finans } \\
\text { yönetimi }\end{array}$ & $\begin{array}{l}\text { Stok analizi } \\
\text { ve } \\
\text { tahmini }\end{array}$ & $\begin{array}{l}\text { Crowdlend } \\
\text { ing }\end{array}$ & Dijital Kimlik \\
\hline
\end{tabular}

Kaynak: Puschmann, 2017.

\section{Fintech Sektörünün Avantajları}

\subsection{Finansal Hizmet Kolaylığı}

Fintech'in varlığı sayesinde, finansal işlemlerin gerçekleştirilme süreci daha kolay hale gelmiştir. Müşteriler ayrıca, ödeme süreci, krediler, transferler veya hisse satın alma ve satma gibi işlemleri kolay ve güvenli bir şekilde gerçekleştirebilirler. Müşteriler, finansal hizmetlere akıllı telefonlar veya dizüstü bilgisayarlar gibi teknolojiler yoluyla erişebilirler. Bu nedenle, çeşitli ihtiyaçları karşılamak için doğrudan bankaya gelmeye gerek yoktur. Bunun gibi finansal konularda teknolojinin varlığı kamuoyunun finansal hizmetleri en üst düzeye çıkarmasında yardımcı olur. Bazı finansal ürünlere ihtiyaç duyan insanlar, sadece çevrimiçi olarak başvuru yaparlar. Finansal hizmetlerin kolaylığı, nispeten hızı bir çalışma sürecine ve finansal olarak ilgili ürünler elde etmek için minimum belge ihtiyacına dayanmaktır (Philippon, 2016).

\subsection{Finansal İşlem Zincirinin Tamamlayıcısı OIması}

Fintech aracılığıyla, ödeme süreci, finansman, satın alma ve satış ve transferler gibi tüm finansal işlemler giderek daha pratik ve güvenlidir. Ayrıca, her şeye yalnızca bir akıllı telefon veya tablet aracılığıyla erişilebilir. Fintech'in rolü, geleneksel bankaların yerine geçmemektedir, bununla birlikte finansal işlem zincirinin bir tamamlayıcısıdır. Fintech'in varlığı, finansal ekosistemi güçlendirmektedir, çünkü insanların finansal ürün alım gücünü artırmaktadır. Bu durum henüz çeşitli finansal hizmetler tarafından ulaşılmayan topluluklara ulaşmada önemli bir fırsat olarak değerlendirilebilir (Philippon, 2016). 


\section{Fintech ve Bankacılık Endüstrisi Arasındaki Farklar}

Fintech'in ticari faaliyetleri çok verimlidir, çok sayıda çalışana ihtiyaç duymaz, lüks bir binaya dahi ihtiyaç duymaz, küçük bir ofis Fintech hizmetleri için yeterlidir.

Fintech, daha verimlidir, çünkü işletme maliyetlerini düşürebilir, böylece daha düşük kredi faizli krediler dağıtabilir. Gelişen Fintech şirketleri, bankacılık piyasasını aşındırma potansiyeline sahip görünmektedir. Düşük maliyet ve hızlı genişleme gücü ile Fintech, bankacılık pazarının konumunu değiştirebilir.

Teknoloji tabanlı finansal şirketlerin veya Finansal Teknoloji'nin (Fintech) ortaya çıkışı, bankacılık sektörünü kendini geliştirmeye zorlamıştır. Fintech yalnızca geleneksel bankacılık gibi ödemeleri, kredileri veya diğer finansal hizmetleri sunmaz. Teknolojik gelişmişlik ve sürekli yenilikçilikle, bankacılık sistemine erişimi olmayan müşterilere ulaşabilirler.

Fintech ayrıca daha kişisel hizmet vermektedir ve bankacılık hizmetlerine erişemeyen kişilere ulaşmaktadır. Bankalar tarafından ulaşılması zor uzak bölgelerde buna dahildir.

Bankacılık endüstrisi ise daha az verimlidir, bu nedenle işletme geliri sonuçlarına kıyasla, karşılanabilecek büyük bir operasyonel yük getirmektedir. (Buchak vd., 2018).

\section{Türkiye'de Fintech Uygulamaları}

Türkiye Fintech Ekosistemi Haritası (Startups. watch) Türkiye'de faaliyet gösteren fintech şirketlerini ödemeler, bankacılık, finansman, kurumsal finansman, sigorta, kitle fonlama, kişisel finansal yönetimi, varlık yönetimi, servet yönetimi, big data, merkezler, kripto başlıkları altında tasnif etmektedir. Literatürü incelediğimizde fintechlerin tasnifinde genel olarak benzer yaklaşımlar görülebilir. Bu alanda başlıca çalışmalardan biri olan Definition of FinTech and Description of the FinTech Industry. FinTech in Germany'ye (Dorfleitner et al., 2017) göre finansal teknolojiler alandaki firmaları başlıca faaliyet konularına göre genellikle finans, ödemeler, varlık yönetimi ve diğer finansal konular olmak üzere dört ana bölümde tasnif etmek mümkündür (Dorfleitner et al., 2017: 6). Aşağıda Şekil 4.1'de sektörün ayrıntılı bir tasnifi gösterilmektedir. 


\section{Şekil 1: Fintech Endüstrisinde Faaliyet Konularına Göre Bölümler}

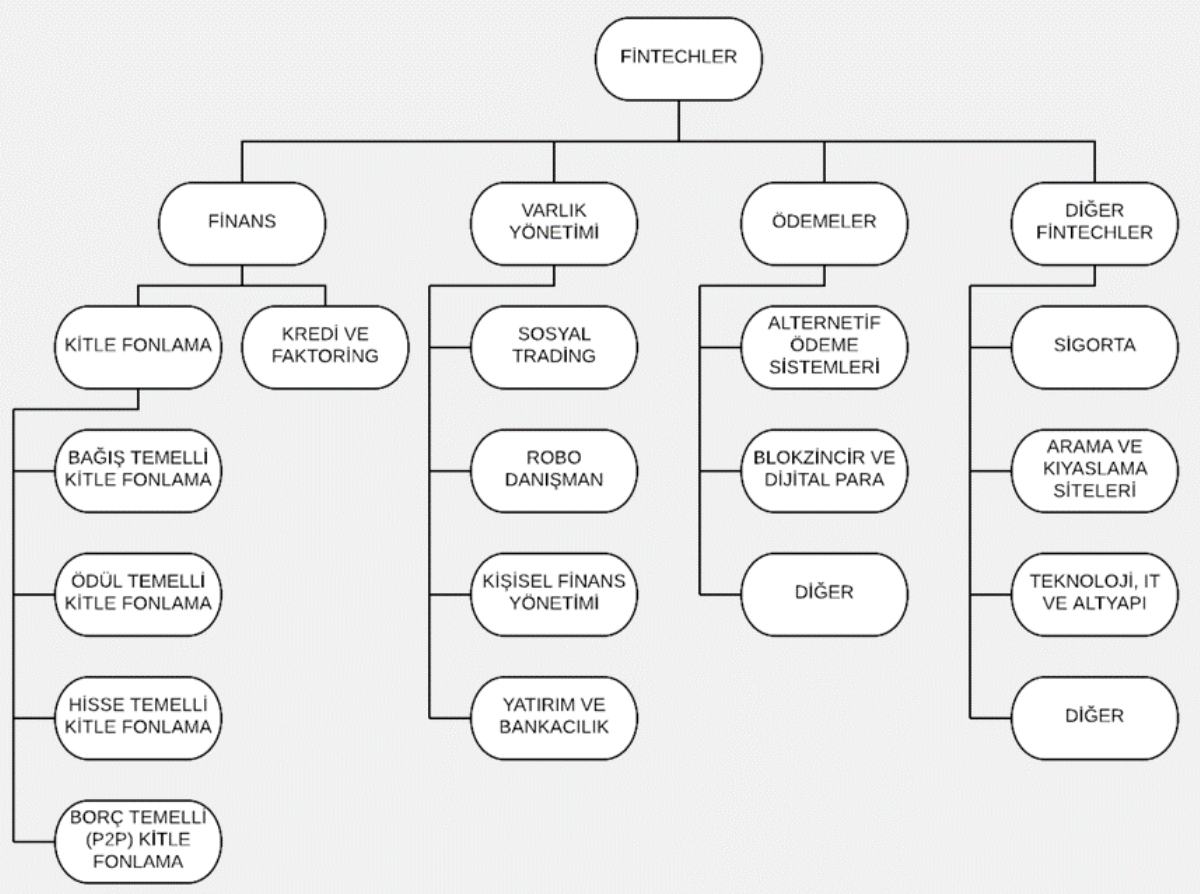

Kaynak: G. Dorfleitner et al., FinTech in Germany, s. 7, Fig. 2.1: Segments of the FinTech Industry

Dünya ile kıyaslandığında istenen yerde olunmasa da örneğin, 2001 yılında Ziraat Bankası tarafından kurulan "Fintek Finansal Teknoloji Hizmetleri A.Ş." (Bkz.: Ziraat Teknoloji), bu konunun ülkemizde de yakından takip edildiğinin bir göstergesidir. 2006'da Avrupa'nın ilk temassız kart uygulaması, 2012'de BKM Express, dijital cüzdan projesi, 2015'te dijital ödeme, 2016'da Troy ödeme sistemi gibi uygulamalar bankacılık ve finans teknolojisi açısından değerlidir. 2015 yılında, Türkiye'de geliştirilen finansal teknolojilere akademik destek, yatırım ve ekosistem desteği verme amacıyla kurulan Finans Teknopark A.Ş. (Borsa İstanbul ve Boğaziçi Üniversitesi), ekosistemi bir çatı altında toplama ve eğitimler vermek için 2016'da faaliyete geçen FinTech Istanbul Platformu, girişimleri hızlandırma programları, (KWORKS Fintech programı, Albaraka Garaj, v.d.), TEB Fintech Future Four ve Garanti BBVA Open Talent yarışmaları sektöre verilen önemi göstermektedir. (Fintechistanbul).

Türkiye Fintech pazarı 200'ün üzerinde şirketle yaklaşık 15 milyar dolar büyüklüğe sahip ve yılda ortalama yüzde 14 büyümektedir. Bir gösterge olarak online ödemelerin toplam işlem hacmi içerisindeki payı 2015 yılında yüzde 10.4 iken 2017'de yüzde $14.5^{\prime}$ e, $2018^{\prime}$ de ise yüzde 16.5'e çıkmıştır (Kırlar vd., 2017: 4; Yeniova, 2018). 
Ödemeler, mobil bankacılık, varlık yönetimi, sermaye piyasaları ve dijital para hizmetleri Türkiye FinTech ekosistemini oluşturan başlıca girişimlerdir ve ön ödemeli kartlar, dijital cüzdan uygulamaları, ödeme takibi, offline ödeme, para transferi, indirim ve sadakat kartları, bütçe yönetimi, tahsilat, POS yönetimi, ön muhasebe, VPOS, yazarkasa, bankacılık yazılımları ve kredi skorlama türünden hizmetler sunulmaktadır. Türkiye'de finansal teknoloji şirketleri üzerinden geçen işlem hacmi 15-20 milyar dolardır. Bu arada, 2018'de kurulan Türkiye Ortak Ödeme Platformu, kullanıcıların kartla veya cep telefonuyla, tek bir uygulama ile para transferi, alışveriş, ulaşım gibi ödeme ihtiyaçlarını karşılayabilmelerine olanak sağlaması bakımından sektöre ivme ve değer kazandırmaktadır (Kırlar vd., 2017: 7; Belli, 2017: 30; Yeniova, 2018).

\section{Şekil 2: Türkiye'de Fintech Yatırımları}

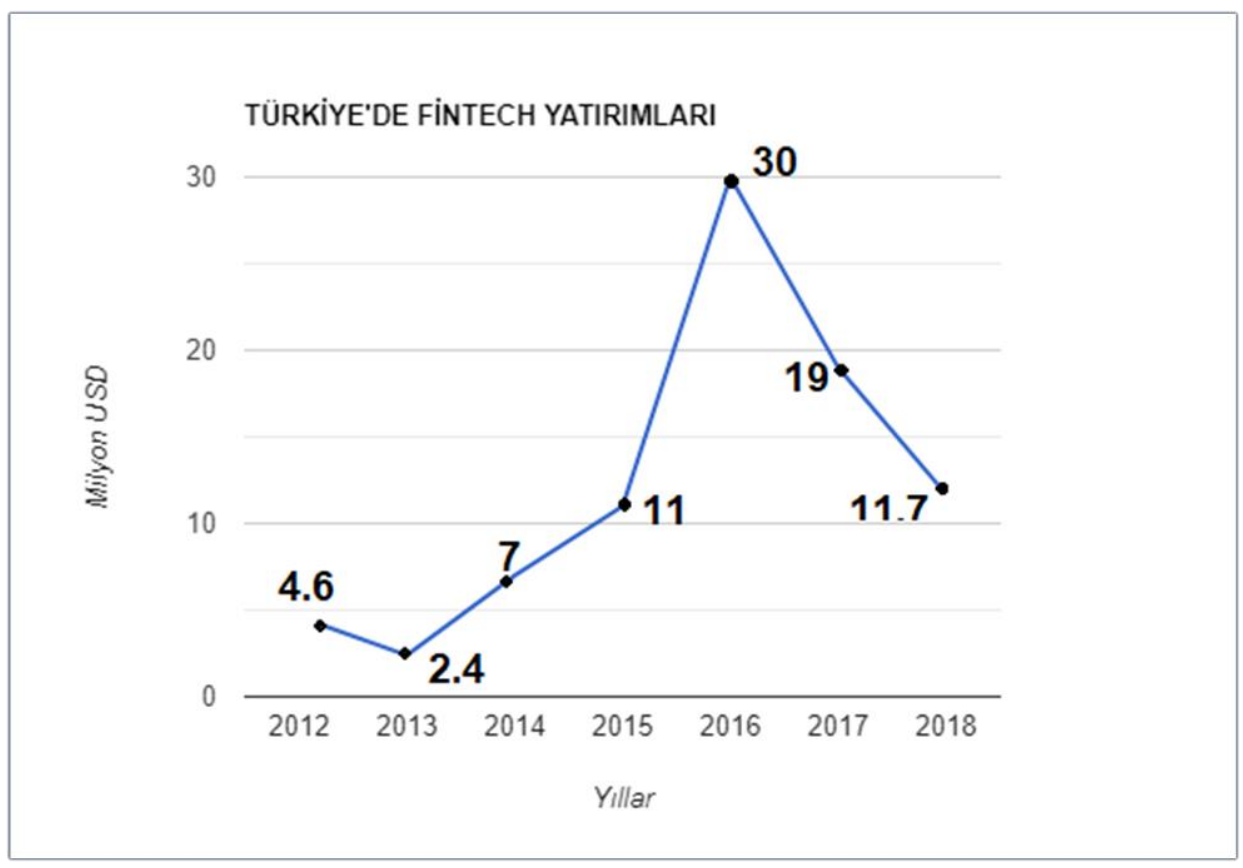

Kaynak: Belli, 2017: 30; Yeniova 2018; Öğütücü, 2019. (Kaynaklarda geçen en yüksek değerler seçilerek hazırlanmıştır.)

\subsection{Türkiye'de Fintech Düzenlemeleri}

Finansal hizmetler, dünyadaki en yoğun denetlenen sektörler arasındadır. Teknoloji finansal hizmetler süreçlerine entegre edildiğinden beri şirketler için yasal sorunlar çoğalmıştır. Bazı durumlarda, problemler teknolojinin bir fonksiyonu olarak değerlendirilebilir. 
Örneğin, işlemlerin otomasyonu ve verilerin dijitalleştirilmesi Fintech sistemlerini bilgisayar korsanlarının saldırılarına karşı savunmasız hale getirmektedir. Kredi kartı şirketlerindeki ve bankalardaki hack vakaları, kötü niyetli kişilerin sistemlere erişme ve onarılamaz hasara neden olma kolaylığının örnekleridir. Bu gibi durumlarda tüketiciler için en önemli sorun, kişisel bilgilerin ve önemli finansal verilerin kötüye kullanılması ile ilgili olacaktır.

Fintech'teki hizmetlerin çeşitliliği nedeniyle, sorunlara tek ve kapsamlı bir yaklaşım oluşturmak zordur. Çoğunlukla, hükümetler mevcut düzenlemeleri kullanmaktadır.

Fintech şirketleri bankacılık sektörünün uymak zorunda olduğu mevzuata tabidirler. Doğal olarak telekomünikasyon ile ilgili mevzuat da kendilerini ilgilendirmektedir (Menteş, 2019: 50). Türkiye'de Fintech şirketlerinin ödeme ve/ veya e-para hizmetleri ile ilgili lisans almak için, Bankacılık Düzenleme ve Denetleme Kurumu'na; işlemleri ödeme sistemi olarak yürütebilmek için de Merkez Bankası'na başvurmaları gerekmektedir. Türkiye'de Fintech ürün ve hizmetlerini düzenleyen başlıca otoriteler Merkez Bankası (TCMB) ile Bankacılık Düzenleme ve Denetleme Kurumu (BBDK)'dur.

BDDK, ödeme ve elektronik para kuruluşlarına faaliyet izinlerini verir, düzenlemeleri yapar ve denetler.

TCMB, sistem işleticisi izinlerini verir, düzenlemeleri yapar ve denetler.

Ayrıca, TCMB, Bankalararası Takas Odaları Merkezi (BTOM), Takas Bank, Merkezi Kayıt Kuruluşu (MKK) ve BKM, ödeme ve menkul kıymet mutabakat sistemlerini işleten ve üzerinde işlem yapan kuruluşlar için düzenlemeleri yapar ve denetler. Rekabet konusundaki sorunlar ise Türk Rekabet Kurumu'na yönlendirilebilir. 
Tablo 2: Fintechleri ilgilendiren Temel Yasal Çerçeve

19.10.2005 tarih ve 5411 sayılı Bankacılık Kanunu

06.12.2012 tarih ve 6362 sayılı Sermaye Piyasası Kanunu

23.10.2014 tarih ve 6563 sayılı Elektronik Ticaretin Düzenlenmesi Hakkında Kanun

11.10.2006 tarih ve 5549 sayılı Suç Gelirlerinin Aklanmasının Önlenmesi Hakkında Kanun

23.02.2006 tarih ve 5464 sayılı Banka Kartları ve Kredi Kartları Kanunu

27.06.2013 tarih ve 6493 sayılı Ödeme ve Menkul Kıymet Mutabakat Sistemleri, Ödeme Hizmetleri ve Elektronik Para Kuruluşları Hakkında Kanun

24.03.2016 tarih ve 6698 sayılı Kişisel Verilerin Korunması Kanunu

Ödeme Hizmetleri ve Elektronik Para ìhracı ile Ödeme Kuruluşları ve Elektronik Para Kuruluşları Hakkında Yönetmelik (RG 27.06.2014 Sayı: 29043) (PSP Yönetmeliği) ve Ödeme Kuruluşları ve Elektronik Para Kuruluşlarının Bilgi Sistemlerinin Yönetimine ve Denetimine İlişkin Tebliğ.

Bağımsız Denetim Kuruluşlarınca Gerçekleştirilecek Banka Bilgi Sistemleri ve Bankacılık Süreçlerinin Denetimi Hakkında Yönetmelik (RG 13.01.2010 sayı 27461). (BBDK tarafından yayınlanmıştır.)

Ödeme ve Menkul Kıymet Mutabakat Sistemlerinin Faaliyetleri Hakkında Yönetmelik (RG 28.06.2014 Sayı 29044) (Merkez Bankası tarafından yayınlanmıştır.)

Ödeme ve Menkul Kıymet Mutabakat Sistemlerinin Gözetimi Hakkında Yönetmelik (RG 28.06.2014 Sayı 29044). (Merkez Bankası tarafından yayınlanmıştır.)

Ödeme ve Menkul Kıymet Mutabakat Sistemlerinde Kullanılan Bilgi Sistemleri Hakkında Tebliğ (Sayı: 2015/7) (RG 09.01.2016 Sayı: 29588). (Merkez Bankası tarafından yayınlanmıştır.)

Banka Kartları ve Kredi Kartları Yönetmeliği (RG 10.03.2007 Sayı 26458). (BBDK tarafından yayınlanmıştır.)

('Melek Yatırımcı'lığı düzenleyen) Bireysel Katılım Sermayesi Yönetmeliği (RG 15.02.2013). (Hazine Müsteşarlığı tarafından yayınlanmıştır.) 
Aktuğ, S.S. (2020). Development of Fintech Sector in Turkey, BILTURK, The Journal of Economics and Related Studies, 2(3), 487-499.

\section{Sonuç}

Türkiye Fintech sektörü, dünyanın geri kalanında olduğu gibi, sektör oyuncuları arasında yüksek düzeyde bir işbirliğine sahne olurken rekabetçi bir sisteme sahip olduğunu kanıtlamıştır. Örneğin, BKM Express dijital cüzdan girişimi, Türkiye'nin önde gelen tüm bankaları ve e-ticaret şirketlerinin işbirliğiyle mümkün olmuştur.

Türk finansal teknolojiler sektörü nispeten gençtir ve ekonomik hacim açısından hala küçük görünmektedir. Bununla birlikte, yenilik ve büyüme için çok fazla fırsat sunmaktadır. Türkiye'nin güçlü bir finansal sektöre sahip olması, canlı ve hızı büyüyen bir Fintech endüstrisi için de başka bir avantajdır ve bunun özellikle ülkenin genç, dinamik ve vasıflı işgücü ile birlikte büyümenin ana itici güçlerinden biri olması beklenebilir.

Türkiye'nin coğrafi konumu da ülkenin yakın gelecekte bölgesel bir finansal teknolojiler merkezi haline gelmesini mümkün kılmaktadır.

Ayrıca, Türkiye'de teknoloji kullanımı ve teknolojik altyapı düzeyleri oldukça iyidir. Bununla, genç nüfusu ve yüksek düzeyde mobil cihaz kullanımı Fintech'in birçok potansiyel dikey pazarda değer yaratmasını mümkün kılmaktadır.

Halen Türkiye'de 200 civarında FinTech şirketi bulunmaktadır. Tahmini pazar büyüklüğü ise yıllık \%14 büyüme ile 15 milyar ABD dolarıdır.

Küresel olarak, Fintech esas olarak ödemeler, mobil bankacılık, varlık yönetimi, borç ödemeleri, InsurTech (sigorta), sermaye piyasaları (finansal modelleme ve analiz yazılımı) ve Blockchain-Bitcoin gibi alanlarda yatırımcıları cezbetmektedir.

Türkiye'de B2B ve B2C faizlerinin büyük kısmı ödemeler, mobil bankacılık, varlık yönetimi, sermaye piyasaları ve dijital paraya odaklanmıştır. Uygulamalar böylece ön ödemeli kartlar, cüzdan uygulamaları, ödemelerin takibi, çevrimdışı ödemeler, para transferleri, indirim ve sadakat kartları, bütçe yönetimi, tahsilat, satış noktası (POS) ödemeleri ve VPOS, kasa yöentimi, bankacılık yazılımı ve kredi stokları olarak karşımıza çıkmaktadır.

Diğer ülkelerde olduğu gibi Türkiye'de de en büyük potansiyel Blockchain teknolojisinde yatmaktadır. Blockchain teknolojisinin özellikle, temassız ödeme sistemleri ve Nesnelerin interneti (loT) gibi mobil erişim için tasarlanmış sistemler olmak üzere birçok alanı etkilemesi beklenmektedir. Bankacılık açısından, üçüncü taraf kuruluşların tüketicilere daha hızlı, güvenli ve esnek uygulamalar ve ürünler sunmasını ve bankaları platformlara dönüştürmesini sağlayarak, PSD2 direktiflerinin uygulanması sayesinde API bankacııığının büyümesi beklenmektedir.

Türkiye'nin InsurTech (sigortacılık) sektörü de ürün ve hizmetleri müşterilere yakınlaştıran mobil uygulamalara doğru ilerliyor ve sigorta ve Blockchain alanındaki yeni girişimlerin sayısı artmaktadır. Ayrıca Türkiye'de Fintech sektörünün gelişimi; elektronik temelli endüstrilerin (e-ticaret) büyümesi için yapısal çözümler 
Aktuğ, S.S. (2020). Development of Fintech Sector in Turkey, BILTURK, The Journal of Economics and Related Studies, 2(3), 487-499.

sağlamakta ve küçük ve orta ölçekli işletmelerin büyümesini ve yeni girişimcilerin doğuşunu teşvik etmektedir.

Türkiye'de Fintech sektörü büyümekte ve yatırımların da artması beklenmektedir. Finans sektörünün, FinTech girişimlerine verdiği güçlü destekle birlikte - şüphesiz sektör üzerinde olumlu bir etkisi olacak ve istikrarlı büyümesinin devam etmesi sağlanacaktır. 
Aktuğ, S.S. (2020). Development of Fintech Sector in Turkey, BILTURK, The Journal of Economics and Related Studies, 2(3), 487-499.

\section{Kaynaklar}

Alper, K., Kara, H. ve Yörükoğlu, M. (2012). Rezerv Opsiyonu Mekanizması, TCMB Ekonomi Notları, Sayı: 28.

Basel Committee on Banking Supervision (BCBS), (2018). Sound Practices: Implications of Fintech Developments for Banks and Bank Supervisors, BIS. https://www.bis.org/bcbs/publ/d431.htm

Belli, M., (2017). The Turkish Fintech Ecosystem, Progress Report 2016, BKM. http://fintech.istanbul/en/wp-content/uploads/2018/03/FinTech-ProgressReport.pdf

Buchak, G., Matvos, G., Piskorski, T., \& Seru, A. (2018). Fintech, Regulatory Arbitrage, and the Rise of Shadow Banks. Journal of Financial Economics, 130(3), 453-483.

Dorfleitner, G. et al., (2017). Definition of FinTech and Description of the FinTech Industry. FinTech in Germany, Springer International Publishing AG 2017.

Eickhoff, M., Muntermann, J., Weinrich, T., (2017). What do FinTechs actually do? A Taxonomy of FinTech Business Models, International Conference on Information SystemsAt: South Korea https://www.researchgate.net/publication/ 320215812_What_do_FinTechs_actually_do_A_Taxonomy_of_FinTech_Bu siness_Models

Fintech İstanbul, (2019). https://fintechistanbul.org/

Kırlar, C., Canko, S., Yazıcı, S. (2017). Türkiye Fintech Ekosistemi, Deloitte Türkiye. https://www2.deloitte.com/content/dam/Deloitte/tr/Documents/finance/turkiye -fintech-ekosistemi.pdf

Leong, K.; Sung, A. (2018). FinTech (Financial Technology): What is It and How to Use Technologies to Create Business Value in Fintech Way?, International Journal of Innovation, Management and Technology. 9 (2): 74-78.

Menteş, A., (2019). Bankacılık Sektörüne Bir Tehdit Unsuru Olarak Finansal Teknoloji Şirketleri, Balkan ve Yakın Doğu Sosyal Bilimler Dergisi, 05 (01), 49-53.

Öğütücü, H., (2019). Türkiye'de 100 Girişime 59,2 Milyon Dolar Yatırım Yapıldı, https://egirisim.com/2019/02/06/turkiyede-2018-yilinda-100-girisime-592-

milyon-dolar-yatirim-yapildi/

Philippon, T. (2016). The Fintech Opportunity (No. w22476). National Bureau of Economic Research.

Puschmann, T. (2017). Fintech. Business \& Information Systems Engineering, 59(1), 69-76.

Sanicola, L. (2017). What is FinTech?. Huffington Post. Retrieved August 20, 2017. 
Schueffel, P. (2017). Taming the Beast: A Scientific Definition of Fintech, Journal of Innovation Management. 4 (4): 32-54.

Softtech Teknoloji Raporu, (2019). https://softtech.com.tr/2019-teknolojiraporu/

SRP Legal, (2019). Fintech in Turkey, https://www.lexology.com/library/detail.aspx?g=d63123cf-b953-43a2b17b-ab780f12b17c

Startups Watch, (2019). Fintech Ecosystem Map v5.0 Turkey, www.startupswatch.com

Yeniova, G., (2018). Fintech'lere Bu Yıl 8,7 Milyon Dolar Geldi, Ekonomist Online, https://www.ekonomist.com.tr/teknoloji/fintechlere-bu-yil-87-milyondolar-geldi.html

Yes Bank, (2019). A Comprehensive Analysis of India's Fintech Landscape 2017-18. http://www.yesfintech.com/data/cms/ifor-report-2018.pdf

Ziraat Teknoloji, (2019).

https://www.ziraatteknoloji.com/hakkimizda/hakkimizda.html 